\title{
Optimization of agro-residues as substrates for Pleurotus pulmonarius production
}

\author{
Nan Wu ${ }^{1 \dagger}$, Fenghua Tian ${ }^{1 \dagger}$, Odeshnee Moodley ${ }^{1}$, Bing Song ${ }^{1}$, Chuanwen Jia ${ }^{1}$, Jianqiang Ye², Ruina Lv ${ }^{1}$, Zhi Qin $^{3}$ \\ and Changtian Li ${ }^{1 *}$
}

\begin{abstract}
The "replacing wood by grass" project can partially resolve the conflict between mushroom production and balancing the ecosystem, while promoting agricultural economic sustainability. Pleurotus pulmonarius is an economically important edible and medicinal mushroom, which is traditionally produced using a substrate consisting of sawdust and cottonseed hulls, supplemented with wheat bran. A simplex lattice design was applied to systemically optimize the cultivation of P. pulmonarius using agro-residues as the main substrate to replace sawdust and cottonseed hulls. The effects of differing amounts of wheat straw, corn straw, and soybean straw on the variables of yield, mycelial growth rate, stipe length, pileus length, pileus width, and time to harvest were demonstrated. Results indicated that a mix of wheat straw, corn straw, and soybean straw may have significantly positive effects on each of these variables. The high yield comprehensive formula was then optimized to include $40.4 \%$ wheat straw, $20.3 \%$ corn straw, $18.3 \%$ soybean straw, combined with $20.0 \%$ wheat bran, and $1.0 \%$ light $\mathrm{CaCO}_{3}(\mathrm{C} / \mathrm{N}=42.50)$. The biological efficiency was $15.2 \%$ greater than that of the control. Most encouraging was the indication that the high yield comprehensive formula may shorten the time to reach the reproductive stage by 6 days, compared with the control. Based on the results of this study, agro-residues may be used as a suitable substitution for sawdust and cottonseed hulls as the main cultivation substrates of $P$. pulmonarius. These results provide a theoretical basis for the "replacing wood by grass" project on edible mushroom cultivation.
\end{abstract}

Keywords: Pleurotus pulmonarius, Mushroom crop, "Replacing wood by grass", Simplex-lattice design, Cultivation, Biological efficiency

\section{Introduction}

This study describes a comprehensive program to utilize herbaceous plants (mainly grasses) to grow edible and medicinal mushrooms, and produce fungi forage and fungi fertilizers with agricultural residues as substrates. "Replacing wood by grass" has many apparent advantages, such as the high utilization of solar energy and resources, lower costs, and shorter production periods to name a few (Sanderson and Reed 2000; Springer et al. 2003). Applying the "replacing wood by grass" system to develop a more ecologically conscious mushroom industry may not only resolve the conflict between mushroom

\footnotetext{
*Correspondence: Ict@jlau.edu.cn

${ }^{\dagger} \mathrm{Nan}$ Wu and Fenghua Tian contributed equally to this work.

${ }^{1}$ Engineering Research Center of Edible and Medicinal Fungi, Ministry

of Education, Jilin Agricultural University, Changchun 130118, China

Full list of author information is available at the end of the article
}

production and ecosystem balance, but it may also lead to great improvements in soil and water conservation, ecological environmental protection, increases of food resources, and the promotion of a sustainable agricultural economy (Lin 2009).

Pleurotus pulmonarius (Fr.) Quél., also known as anchovies and Indian abalone mushrooms (Li et al. 2015), is most commonly known as the grey oyster mushroom, which is characterized by a grayish colored sporophore, which has a fleshy texture and produces an aromatic, not anise-like aroma (Lechner et al. 2004). P. pulmonarius is formally classified in the following categories: Fungi, Basidiomycota, Agaricomycetes, Agaricomycetidae, Agaricales, Pleurotaceae, Pleurotus (http://www.indexfungo rum.org/Names/Names.asp). P. pulmonarius has an outstanding reputation as an edible mushroom that has been used for centuries as a food and food flavoring because 
of its highly desirable taste qualities and unique aroma (Oliveira et al. 2002; Zhang et al. 2013). It also contains a large range of proteins, polysaccharides, essential amino acids, a high potassium to sodium ratio, and multivitamins, including niacin and riboflavin (Velázquez-Cedeño et al. 2002; Stanley et al. 2011). P. pulmonarius is widely marketable and sells well in southeast Asia, Japan, and several other countries. However, it is more expensive than other mushrooms, such as Flammulina velutipes and $P$. ostreatus. Recently, many studies have confirmed that P. pulmonarius has pharmacological properties, such as antioxidants, anti-cholinesterase, antitumor, antibacterial, immuno-modulating, anti-inflammatory, aids in resisting potential vascular complications, and may reduce blood sugar levels (Olufemi et al. 2012; Smiderle et al. 2012; Xu et al. 2012; Wahab et al. 2014; Ge 2015; Nguyen et al. 2016; Ni 2016; Zhang et al. 2016).

Sawdust and cottonseed hulls are the main materials for the traditional cultivation of $P$. pulmonarius. However, the price of cottonseed shells has risen to 282 US dollars per ton (Liu et al. 2011). Complicating the matter, the logging of trees has been declared as a social, environmental, and global issue. In China, there are abundant agro-residue resources, such as wheat straw, corn cobs, rice straw, soybean straw, rice straw, peanut straw, rape straw, and corn straw. Substrates play an indispensable role in the nutritional composition of oyster mushroom and previous studies have found astounding differences in both proximate and mineral composition of Pleurotus when these mushrooms are raised in different substrates (Sarker et al. 2007; Bhattacharjya et al. 2015). The great potential of this industry is derived from its promise of saving land and labor, its eco-friendly nature, and its low required startup capital. For these reasons, it is urgent to find new substrates for mushroom crop cultivation in relation to the "replacing wood by grass" project.

The objectives of this study were to evaluate different agro-residues as potential substrates for $P$. pulmonarius cultivation using a simplex-lattice design method, optimize substrate composition, and evaluate the combined effects of the substrate on mycelial growth rates, yield, and fruiting body traits of $P$. pulmonarius. This study was also intended to provide information for the further development of the "replacing wood by grass" project in China by investigating a variety of agro-residues that could replace sawdust and cottonseed hulls in P. pulmonarius cultivation.

\section{Materials and methods}

Microorganism and spawn preparation

Mycelia of P. pulmonarius CCMJAU 201708 were obtained from the Engineering Research Center of the Chinese Ministry of Education for Edible and Medicinal
Fungi of Jilin Agricultural University, China. Mycelia were cultured on potato dextrose agar (PDA) in a Petri dish for 6 days at $24{ }^{\circ} \mathrm{C}$ in darkness. When mycelia had grown to completely cover the media, mycelia with a diameter of $5 \mathrm{~mm}$ were collected for use as future inoculum sources.

Liquid spawn was prepared by culturing mycelial plugs ( $2 \mathrm{~mm}$ in diameter, 10 plugs/flask) in $1 \mathrm{~L}$ flasks containing $400 \mathrm{~mL}$ of liquid media, while shaking $(150 \mathrm{rpm} / \mathrm{min})$ in a rotatory incubator at $24{ }^{\circ} \mathrm{C}$ for 9 days, in darkness. Liquid media consisted of maize meal $(40 \mathrm{~g} / \mathrm{L})$, glucose $(20 \mathrm{~g} / \mathrm{L})$, peptone $(1 \mathrm{~g} / \mathrm{L}), \mathrm{KH}_{2} \mathrm{PO}_{4}(10 \mathrm{~g} / \mathrm{L})$, and $\mathrm{MgSO}_{4}$ $(5 \mathrm{~g} / \mathrm{L})$ at a of $\mathrm{pH} 6.5$ (Wu 2011).

\section{Substrate preparation}

Various agro-residues, including wheat straw, rice straw, soybean straw, corn straw, corn cobs, peanut straw, rape straw, and supplements, including wheat bran and light $\mathrm{CaCO}_{3}$, for the cultivation of $P$. pulmonarius were purchased from the mushroom base of Jilin Agricultural University, Changchun, China. All agro-residues were chopped, air dried, and ground into a fine powder.

\section{Screening of appropriate agro-residue substrates in Petri dishes}

The CK (control) substrate, or standard formulation, for screening and comparing additional substrates was comprised of $40.0 \%$ sawdust, $39.0 \%$ cottonseed hulls, $20.0 \%$ wheat bran, and $1.0 \%$ calcium carbonate (Fan et al. 2016). In the additional substrate formulations, or the treatment groups, one of seven kinds of agro-residues (wheat straw, rice straw, soybean straw, corn straw, corn cobs, peanut straw, rape straw) was used to make up $79.0 \%$ of the total substrate by replacing sawdust and cottonseed hulls. All the substrates were pressed into separate Petri dishes (90 $\mathrm{mm}$ in diameter) to a height of $5 \mathrm{~mm}$ and autoclaved at $121{ }^{\circ} \mathrm{C}$ for $1 \mathrm{~h}$.

Mycelial plugs, $5 \mathrm{~mm}$ in diameter, were cut from the leading edge of actively growing cultures on PDA plates. One plug was inoculated into the center of each of the Petri dishes containing the various agro-residue substrates. The Petri dishes were incubated in darkness at $24{ }^{\circ} \mathrm{C}$ for 7 days. Each treatment was replicated five times. Mycelial growth rates were measured as subsequently described. Every day, the radial growth of each treatment was observed. The diameter of each colony was measured on two perpendicular axes bisecting the center of the colony, then the mean value over time was calculated to reflect the growth rate of the mycelia. The three agroresidues associated with the fastest mycelial growth rates were then considered in further analyses. 


\section{Substrate formulations}

A one-factor-at-a-time (OFAT) method (Singh et al. 2011) was used to determine the initial range of the three independent variables. Based on results from the Petri dishes, the variables $X_{1}=$ wheat straw, $X_{2}=$ corn straw, and $X_{3}=$ soybean straw were selected for a simplex-lattice design. These were then mixed in various combinations to determine the optimal substrate composition for the cultivation of $P$. pulmonarius.

$$
\begin{aligned}
& 0 \% \leq X_{1} \leq 100 \%, \text { wheat straw } \\
& 0 \% \leq X_{2} \leq 100 \%, \text { corn straw } \\
& 0 \% \leq X_{3} \leq 100 \%, \text { soybean straw } \\
& X_{1}+X_{2}+X_{3}=100 \%
\end{aligned}
$$

Ten possible mixture formulations were designed with the main ingredient accounting for $79.0 \%$ of the total substrate (Table 1). The substituting ingredients were wheat straw, corn straw, and soybean straw, as previously described. The main ingredient of the control substrate mixture (CK) was composed of $40.0 \%$ sawdust and $39.0 \%$ cottonseed hulls. The remainder of all formulations consisted of $20.0 \%$ wheat bran, $1.0 \%$ light $\mathrm{CaCO}_{3}$, and water at a $\mathrm{pH}$ of 7.0. Environmental conditions were kept constant across all treatments and each treatment was replicated three times.

\section{Model analysis}

The Scheffé model was fitted using a polynomial quadratic equation in order to correlate the response variable (Y) with the independent variables $(\mathrm{X})$. The Eq. was as follows:

$$
\mathrm{Y}=\sum_{1 \leq i \leq q} \beta_{i} X_{i}+\sum_{1 \leq i \leq j \leq q} \beta_{i} X_{i} X_{j}
$$

The mixture experiment and optimization design followed previously described methods (Scheffe 1963;

Table 1 Experimental design and model formulations for cultivation materials

\begin{tabular}{llll}
\hline Formulation & \multicolumn{3}{l}{ Substrate mixture ratio } \\
\cline { 2 - 4 } & $\mathbf{X}_{\mathbf{1}}(\%)$ & $\mathbf{X}_{\mathbf{2}}(\%)$ & $\mathbf{X}_{\mathbf{3}}(\mathbf{\%})$ \\
\hline 1 & 100 & 0 & 0 \\
2 & 0 & 100 & 0 \\
3 & 0 & 0 & 100 \\
4 & 50 & 50 & 0 \\
5 & 50 & 0 & 50 \\
6 & 0 & 50 & 50 \\
7 & 33.3 & 33.3 & 33.3 \\
8 & 16.7 & 16.7 & 66.7 \\
9 & 16.7 & 66.7 & 16.7 \\
10 & 66.7 & 16.7 & 16.7 \\
\hline $\mathbf{X}_{1}-w h a t s t a X_{2}-c o n$
\end{tabular}

$\mathrm{X}_{1}$-wheat straw; $\mathrm{X}_{2}$-corn straw; $\mathrm{X}_{3}$-soybean straw
Lundstedt et al. 1998; Yang et al. 2016; Song et al. 2018) (Table 1).

\section{Cultivation method}

Substrates were prepared from the various agro-residue components as $79.0 \%$ of the main substrate, supplements (wheat bran and light $\mathrm{CaCO}_{3}$ ) as $21.0 \%$ of the substrate mixed with sterilized water was added to $\pm 72.5 \%$. A total of $500.0 \mathrm{~g}$ of each of the substrates (dry weight of $150.0 \mathrm{~g}$ ) was used to fill a $20 \mathrm{~cm} \times 17.5 \mathrm{~cm} \times 0.05 \mathrm{~cm}$ polypropylene bag, with a $2.5 \mathrm{~cm}$ collar at the bag mouth. The filled bags were then autoclaved at $121^{\circ} \mathrm{C}$ for $1 \mathrm{~h}$. After cooling below $20^{\circ} \mathrm{C}$, each bag was then inoculated with $15 \mathrm{~mL}$ of liquid spawn of $P$. pulmonarius.

After inoculation, all bags were incubated in the dark at $22-24{ }^{\circ} \mathrm{C}$, at a carbon dioxide $\left(\mathrm{CO}_{2}\right)$ concentration below $2500 \mathrm{ppm}$. After it mycelia filled the bags, each formulation was cultivated for four additional days to ensure physiological maturity. Subsequently, each bag was cut to create two "V" shaped holes on the surface using a sterilized knife. The bags were then transferred to a cultivation room. All treatments were maintained in the same room under the same conditions $\left(15-17^{\circ} \mathrm{C}\right.$, $90-95 \%$ relative humidity, 400-700 ppm $\mathrm{CO}_{2}$ concentration, under a 200 LUX light source for $10 \mathrm{~h} /$ day) to facilitate basidiocarp growth. Mushroom harvest times were recorded as they occurred. After harvest, the mushroom yield corresponding to each bag was weighed. The harvest included 20 bags from each treatment with three replicates; all data were used for statistical analyses.

\section{Data collection}

The radial growth of each formula in Petri dishes, time to bud formation, growth parameters pertaining to a single fruiting body (length and width of the stipe, and length, thickness, and width of the pileus measured using a Vernier caliper), time to harvest, and reproductive stage and yield parameters including total fresh weight $(\mathrm{g})$ were collected. The biological efficiency (BE) for each substrate formulation was calculated as follows:

$$
B E(\%)=\frac{\text { Fresh weight of mushroom }}{\text { Dry weight of substrate }} \times 100
$$

$$
\text { Reproductive stage }(d)=\text { Harvest time }- \text { Bud time }
$$

\section{Statistical analyses}

Design expert statistical software package V 8.0.6.1 was used to construct a regression analysis. A quadratic multiple regression fitting of yield, mycelial growth rate, stipe length, pileus length, pileus width, and time to harvest against the substrate formula ingredients was performed using the Scheffé quadratic polynomial regression model. The regression equation for each evaluation index was 
established. The influence of the interaction between the three main ingredients on the evaluation index was analyzed. The optimization function was used to set the variation range and the expected response value for each ingredient. Beginning with a random combination, the steepest slope prediction was performed until the target response value was reached. The optimized yield formula derived from the regression analysis was verified, an analysis of variance (ANOVA) analysis was performed to estimate the statistical parameters using SPSS Statistics 17, and finally, the significant differences between the means were determined by a Student-Newman-Keuls test (Yang et al. 2016). Unless otherwise stated, the differences were considered statistically significant at $P<0.05$.

\section{Verification test}

The substrate formula, which was determined to be optimal according to the previous experiment, was tested against the CK substrate formula at the mushroom base at Jilin Agricultural University. The results were analyzed to determine the feasibility of using the treatment substrate formula in place of the CK.

\section{Results}

\section{Screening results of agro-residue substrates}

Based on the results obtained from screening the Petri dishes, there were significant $(\mathrm{P}<0.05)$ differences between the various agro-residues (Fig. 1). Soybean straw was determined to be the best for the mycelial growth of P. pulmonarius. The mycelial growth rate in the soybean straw was significantly higher at $3.50 \mathrm{~mm} /$ day than in the CK, which was $3.39 \mathrm{~mm} /$ day. Wheat straw and corn straw followed, with mycelial growth rates of $3.27 \mathrm{~mm} /$ day and $3.00 \mathrm{~mm} /$ day, respectively. The mycelial growth rate in the rice straw was slowest at $2.30 \mathrm{~mm} /$ day. From these results, soybean straw, wheat straw, and corn straw were chosen as the appropriate agro-residue substrates for the subsequent D-optimum experiment.

\section{Effects of different agro-residue formulations on time to harvest}

With the statistical analysis of the time to harvest for each substrate formula (Additional file 1: Table S1), the following regression model equation between the time to harvest and each ingredient was developed:

$$
\begin{aligned}
Y= & 42.74 X_{1}+42.41 X_{2}+36.08 X_{3}+4.97 X_{1} X_{2} \\
& -5.02 X_{1} X_{3}+11.64 X_{2} X_{3}-29.33 X_{1}^{2} X_{2} X_{3} \\
& -304.75 X_{1} X_{2}^{2} X_{3}-17.31 X_{1} X_{2} X_{3}^{2} \\
& \left(R^{2}=0.8597\right)
\end{aligned}
$$

Using the regression model, the predicted time to harvest was calculated for each substrate formula. The linear correlation coefficient results for time to harvest was relatively high at $R^{2}=0.8597$. The statistical analysis showed that the $P$ values of both the mixed linear model and the quadratic regression model were $<0.0001$, indicating that these two models were very significant and well fitted to the relationship between ingredients and time to harvest. Additionally, the correlation coefficient indicated that the equation model had an $85.97 \%$ goodness-of-fit to the experimental data. The analysis of variance (ANOVA) for $Y$ was shown in Additional file 1: Table S1. The $P$ value showed the probability of whether the time to harvest was affected by the different agro-residues. The terms which had $P$ values $<0.05$ had an important effect on the time to harvest. The coefficients of the independent variables in the equation reflect the degree of influence of the independent variable in the equation, i.e., the degree of contribution. As seen

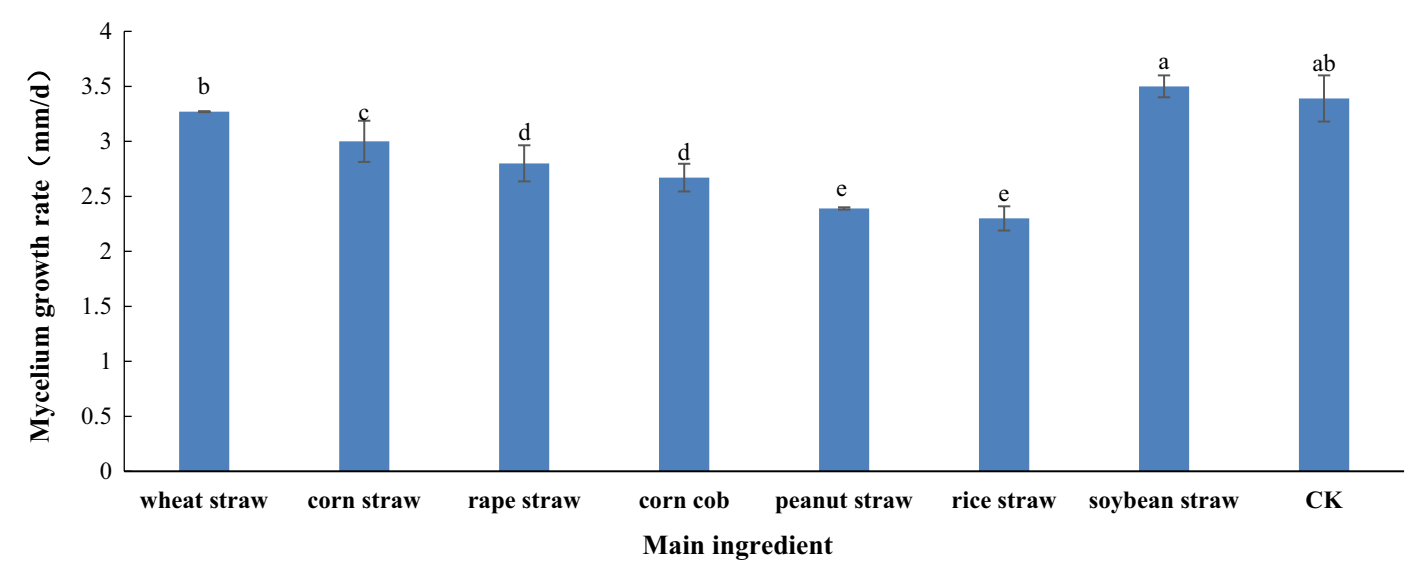

Fig. 1 Effect of different agro-residue substrates on mycelial growth rate in Petri dishes. Mean values followed by no letters are not significantly different at a level of $5 \%(P<0.05)$ 
in the regression model, the equation coefficients were $\mathrm{K}$ $\left(\mathrm{X}_{1}\right)=42.74>\mathrm{K} \quad\left(\mathrm{X}_{2}\right)=42.41>\mathrm{K} \quad\left(\mathrm{X}_{3}\right)=36.08$. Combined with the interaction analysis, and based on the $\mathrm{f}$-value and $P$ value, the interaction between $\mathrm{X}_{2} \mathrm{X}_{3}$ and $\mathrm{X}_{1} \mathrm{X}_{2}^{2} \mathrm{X}_{3}$ significantly affected the time to harvest. It could be concluded that the time to harvest was changed by the appropriate selection of the $X_{1}, X_{2}$, and $X_{3}$ levels. Interactions between $\mathrm{X}_{1} \mathrm{X}_{2}^{2} \mathrm{X}_{3}$ may significantly reduce the time until harvest and interactions between $\mathrm{X}_{2} \mathrm{X}_{3}$ may significantly increase the time until harvest.

\section{Effects of different agro-residue substrate formulations on stipe length}

With the statistical analysis of the stipe length for each substrate formula (Additional file 1: Table S2), the following regression model equation between the stipe length and each ingredient was developed:

$$
\begin{aligned}
Y= & 32.83 X_{1}+34.94 X_{2}+42.84 X_{3}-3.92 X_{1} X_{2} \\
& +23.33 X_{1} X_{3}-28.19 X_{2} X_{3}+743.05 X_{1}^{2} X_{2} X_{3} \\
& +401.26 X_{1} X_{2}^{2} X_{3}-306.44 X_{1} X_{2} X_{3}^{2} \\
\left(R^{2}=\right. & 0.9241)
\end{aligned}
$$

The linear correlation coefficient for stipe length was relatively high at $R^{2}=0.9241$. Additionally, the correlation coefficient indicated that the equation model had a 92.41\% goodness-of-fit with the experimental data. As seen in the regression model, the equation coefficients were $\mathrm{K}$ $\left(\mathrm{X}_{3}\right)=42.84>\mathrm{K}\left(\mathrm{X}_{2}\right)=34.94>\mathrm{K}\left(\mathrm{X}_{1}\right)=32.83$. These results indicated that soybean straw had the greatest degree of contribution to the stipe length of $P$. pulmonarius.

Combined with the interaction analysis, and based on the $\mathrm{f}$-value and $P$ value, the interactions between $\mathrm{X}_{1} \mathrm{X}_{3}, \mathrm{X}_{2} \mathrm{X}_{3}$, $\mathrm{X}_{1}^{2} \mathrm{X}_{2} \mathrm{X}_{3}, \mathrm{X}_{1} \mathrm{X}_{2}^{2} \mathrm{X}_{3}$, and $\mathrm{X}_{1} \mathrm{X}_{2} \mathrm{X}_{3}^{2}$, were shown to have significantly affected stipe length (Additional file 1: Table S2). Interactions between $\mathrm{X}_{2} \mathrm{X}_{3}$ and $\mathrm{X}_{1} \mathrm{X}_{2} \mathrm{X}_{3}^{2}$ may significantly reduce stipe length. Interactions between $X_{1} X_{3}, X_{1}^{2} X_{2} X_{3}$, and $X_{1} X_{2}^{2} X_{3}$ may significantly increase stipe length.

\section{Effects of different agro-residue formulations on pileus length}

With the statistical analysis of the pileus length for each substrate formula (Additional file 1: Table S3), the following regression model equation between the pileus length and each ingredient was developed:

$$
\begin{aligned}
Y= & 35.06 X_{1}+48.00 X_{2}+50.20 X_{3}+6.65 X_{1} X_{2} \\
& -0.021 X_{1} X_{3}-17.22 X_{2} X_{3}+768.97 X_{1}^{2} X_{2} X_{3} \\
& -422.50 X_{1} X_{2}^{2} X_{3}+389.72 X_{1} X_{2} X_{3}^{2} \\
\left(R^{2}=\right. & 0.9581)
\end{aligned}
$$

The statistical analysis showed that the $P$ values of both the mixed linear model and the quadratic regression model were $<0.0001$, which indicated that these two models were very significant and well fitted to the relationship between ingredients and the pileus length. Additionally, the correlation coefficient indicated that the equation model had a 95.81\% goodness-of-fit with the experimental data. As seen in the regression model, the equation coefficients were $\mathrm{K}$ $\left(\mathrm{X}_{3}\right)=50.20>\mathrm{K}\left(\mathrm{X}_{2}\right)=48.00>\mathrm{K} \quad\left(\mathrm{X}_{1}\right)=35.06$. This result indicated that soybean straw had the greatest degree of contribution to the pileus length of $P$. pulmonarius.

Combined with the interaction analysis, based on the $\mathrm{f}$-value and $P$ value, the interactions between $\mathrm{X}_{1} \mathrm{X}_{2}, \mathrm{X}_{2} \mathrm{X}_{3}$, $\mathrm{X}_{1}^{2} \mathrm{X}_{2} \mathrm{X}_{3}, \mathrm{X}_{1} \mathrm{X}_{2}^{2} \mathrm{X}_{3}$, and $\mathrm{X}_{1} \mathrm{X}_{2} \mathrm{X}_{3}^{2}$ were shown to have significantly affected the pileus length (Additional file 1 : Table S3). Interactions between $\mathrm{X}_{2} \mathrm{X}_{3}$ and $\mathrm{X}_{1} \mathrm{X}_{2}^{2} \mathrm{X}_{3}$ may significantly reduce the pileus length, and the interactions between $\mathrm{X}_{1} \mathrm{X}_{2}, \mathrm{X}_{1}^{2} \mathrm{X}_{2} \mathrm{X}_{3}$ and $\mathrm{X}_{1} \mathrm{X}_{2} \mathrm{X}_{3}^{2}$ may significantly increase the pileus length.

\section{Effects of different agro-residue substrate formulations on pileus width}

With the statistical analysis of the pileus width for each substrate formula (Additional file 1: Table S4), the following regression model between the pileus width and each ingredient was developed:

$$
\begin{aligned}
Y= & 41.10 X_{1}+46.77 X_{2}+53.17 X_{3}+10.40 X_{1} X_{2} \\
& +4.52 X_{1} X_{3}-40.41 X_{2} X_{3}+889.89 X_{1}^{2} X_{2} X_{3} \\
& -573.34 X_{1} X_{2}^{2} X_{3}+86.31 X_{1} X_{2} X_{3}^{2} \\
& \left(R^{2}=0.9663\right)
\end{aligned}
$$

The ANOVA for $Y$ is shown in Additional file 1: Table S4. The linear correlation coefficient for the pileus width was relatively high at $R^{2}=0.9241$. As seen in the regression model, the equation coefficients were $\mathrm{K}\left(\mathrm{X}_{3}\right)=53.17>\mathrm{K}$ $\left(\mathrm{X}_{2}\right)=46.77>\mathrm{K} \quad\left(\mathrm{X}_{1}\right)=41.10$, which indicated that the degree of contribution of each ingredient to the pileus width was as follows: $X_{3}$ (soybean straw) $>X_{2}$ (corn straw) $>X_{1}$ (wheat straw). This result indicated that soybean straw had the greatest degree of contribution to the pileus width of $P$. pulmonarius.

Combined with the interaction analysis, based on the $\mathrm{f}$-value and $P$ value, the interactions between $\mathrm{X}_{1} \mathrm{X}_{2}, \mathrm{X}_{2} \mathrm{X}_{3}$, $\mathrm{X}_{1}^{2} \mathrm{X}_{2} \mathrm{X}_{3}$, and $\mathrm{X}_{1} \mathrm{X}_{2}^{2} \mathrm{X}_{3}$ were shown to have significantly affected the pileus width (Additional file 1: Table S4). Interactions between $\mathrm{X}_{2} \mathrm{X}_{3}$ and $\mathrm{X}_{1} \mathrm{X}_{2}^{2} \mathrm{X}_{3}$ may significantly reduce the pileus width. Interactions between $\mathrm{X}_{1} \mathrm{X}_{2}, \mathrm{X}_{1}^{2} \mathrm{X}_{2} \mathrm{X}_{3}$ may significantly increase the pileus width. 


\section{Effects of different agro-residue formulations on mycelial growth rate}

With the statistical analysis of the mycelial growth rate for each substrate formula (Additional file 1: Table S5), the following regression model between the mycelial growth rate and each ingredient was developed:

$$
\begin{aligned}
Y= & 0.39 X_{1}+0.38 X_{2}+0.33 X_{3}-0.18 X_{1} X_{2} \\
& -0.16 X_{1} X_{3}-0.004568 X_{2} X_{3}+0.18 X_{1}^{2} X_{2} X_{3} \\
& -9.22 X_{1} X_{2}^{2} X_{3}+7.34 X_{1} X_{2} X_{3}^{2} \\
\left(R^{2}=\right. & 0.9906)
\end{aligned}
$$

The linear correlation coefficient for the pileus width was relatively high at $R^{2}=0.9906$. As seen in the regression model, the equation coefficients were $\mathrm{K}\left(\mathrm{X}_{1}\right)=0.39>\mathrm{K}$ $\left(X_{2}\right)=0.38>K\left(X_{3}\right)=0.33$. This indicated that wheat straw had the greatest degree of contribution to the mycelial growth rate of $P$. pulmonarius.

The interactions between $X_{1} X_{2}, X_{1} X_{3}, X_{1} X_{2}^{2} X_{3}$, and $\mathrm{X}_{1} \mathrm{X}_{2} \mathrm{X}_{3}^{2}$ were shown to have significantly affected the mycelial growth rate. It was concluded that the mycelial growth rate may be changed by the appropriate selection of the $X_{1}$, $\mathrm{X}_{2}$, and $\mathrm{X}_{3}$ levels (Additional file 1: Table S5). Interactions between $\mathrm{X}_{1} \mathrm{X}_{2}, \mathrm{X}_{1} \mathrm{X}_{3}$, and $\mathrm{X}_{1} \mathrm{X}_{2}^{2} \mathrm{X}_{3}$ may significantly reduce the mycelial growth rate, and $X_{1} X_{2} X_{3}^{2}$ may significantly increase the mycelial growth rate.

\section{Effects of different agro-residue substrate formulations on yield}

With the statistical analysis of the yield for each substrate formula (Additional file 1: Table S6), the following regression model between the yield and each ingredient was developed:

$$
\begin{aligned}
Y= & 2037.37 X_{1}+2498.48 X_{2}+2916.14 X_{3}+1256.89 X_{1} X_{2} \\
& -1163.46 X_{1} X_{3}-74.92 X_{2} X_{3}+80178.75 X_{1}^{2} X_{2} X_{3} \\
& -11917.38 X_{1} X_{2}^{2} X_{3}-20445.90 X_{1} X_{2} X_{3}^{2} \\
& \left(R^{2}=0.8747\right)
\end{aligned}
$$

Using the regression model, the predicted yield was calculated for each substrate formula, and the measured yield and the predicted yield were found to be very similar. As seen in the regression model, the equation coefficients were $\mathrm{K} \quad\left(\mathrm{X}_{3}\right)=2916.14>\mathrm{K} \quad\left(\mathrm{X}_{2}\right)=2498.48>\mathrm{K}$ $\left(X_{1}\right)=2037.37$, which indicated that the degree of contribution of each ingredient to the yield was as follows: $\mathrm{X}_{3}$ (soybean straw) $>\mathrm{X}_{2}$ (corn straw) $>\mathrm{X}_{1}$ (wheat straw). This result indicated that soybean straw had the greatest degree of contribution to the yield of $P$. pulmonarius.
The interactions between $\mathrm{X}_{1} \mathrm{X}_{2}, \mathrm{X}_{1} \mathrm{X}_{3}, \mathrm{X}_{1}^{2} \mathrm{X}_{2} \mathrm{X}_{3}$, and $\mathrm{X}_{1} \mathrm{X}_{2} \mathrm{X}_{3}^{2}$ were shown to have significantly affected the yield (Additional file 1: Table S6). Interactions between $\mathrm{X}_{1} \mathrm{X}_{3}$ and $\mathrm{X}_{1} \mathrm{X}_{2} \mathrm{X}_{3}^{2}$ may significantly reduce the yield, and interactions between $\mathrm{X}_{1} \mathrm{X}_{2}$ and $\mathrm{X}_{1}^{2} \mathrm{X}_{2} \mathrm{X}_{3}$ may significantly increase the yield.

\section{High-yielding formula and verification test}

Using the yield, mycelial growth rate, stipe length, pileus length, pileus width, and the time to harvest as the evaluation indices, and setting the variation range and expected response value of each ingredient, a steepest slope prediction was carried out based on the regression equation beginning from a random combination, and a high yield comprehensive formula with the agro-residues was generated. The resulting substrate formula was as follows: $51.1 \%$ wheat straw $\left(\mathrm{X}_{1}\right), 25.7 \%$ corn straw $\left(\mathrm{X}_{2}\right)$, and $23.2 \%$ soybean straw. These values were then multiplied by the coefficient of $79.0 \%$ and thus converted to the final values of $40.4 \%$ wheat straw, $20.3 \%$ corn straw, $18.3 \%$ soybean straw, and $20.0 \%$ wheat bran and $1.0 \%$ light $\mathrm{CaCO}_{3}$ combined, which is the high yield comprehensive ( $\mathrm{HC}$ ). Using this substrate formula, the measured yield (first mushroom) reached $82.30 \mathrm{~g} / \mathrm{bag}$, which was similar to the predicted fitted value. These results showed that by using this formula, the yield (first mushroom) was increased by $21.8 \%$ compared to the CK $(67.67 \mathrm{~g} / \mathrm{bag})$, and the $\mathrm{BE}$ was $15.2 \%$ greater than that of the CK (HC:118.6\%; CK:103.4\%). The mycelial growth rate, single-fruitingbody stipe length, stipe width, pileus length, pileus width, pileus thickness, time to bud formation, time to harvest, and the reproductive stage, as they pertain to the high yield comprehensive formula, were also examined. The single-fruiting-body pileus length $(69 \mathrm{~mm})$, pileus width (87 mm), and pileus thickness $(23 \mathrm{~mm})$ of P. pulmonarius for the high yield comprehensive formula were greater than those of the CK, which were $68 \mathrm{~mm}, 66 \mathrm{~mm}$, and $20 \mathrm{~mm}$, respectively. However, the time to bud formation of the high yield comprehensive formula was delayed by 4 days compared to the CK, even when the growth cycle was started 2 days in advance. Given this delay, the reproductive stage of the high yield comprehensive formula was 6 days shorter than that of the CK (Additional file 1: Table S7).

\section{Discussion}

Several edible fungi have traditionally been cultivated on forest wood (sawdust); however, due to the recent efforts to manage forest resources, the use of agro-forestry products for its cultivation is no longer considered to be sustainable (Song et al. 2018). Wood rot fungus straw is being utilized for the production of Pleurotus ostreatus, Pleurotus eryngii, Pleurotus cystidiosus, Lentinula 
edodes and Flammulina velutipes, which can be cultivated with agro-residues, such as crop straws, either with composting or non-composting (Moonmoon et al. 2010; Hoa et al. 2015; Pedri et al. 2015; Rezaeian and Pourianfar. 2016; Papadaki et al. 2019). However, to date, there has been no study focused on optimizing the substrate formula for cultivating Pleurotus by the simple lattice method. Pleurotus primarily produces laccase and is one of the most widely cultivated, edible fungi in the world (Souza et al. 2002; Zhang et al. 2011).

The design of the simple lattice method is a basic mixing design method. Through regression analysis, the quantitative relationship between the ratio of the main material matrix and the evaluation index can be obtained, and therefore the optimum formula can be achieved (Yang et al. 2016). Consequently, in this study, the use of different agro-residues (wheat straw, rice straw, soybean straw, corn straw, corn cob, peanut straw, and rape straw) was investigated to find an substrate to replace sawdust and cottonseed hulls for cultivating P. pulmonarius. A statistical model for optimizing production and evaluating the effects of the alternative substrate formula on yield, mycelial growth rate, stipe length, pileus length, pileus width, and time to harvest was also described.

In the present study, three kinds of common agro-residues, wheat straw, corn straw, and soybean straw, were used as the main ingredients. The yield, mycelial growth rate, stipe length, pileus length, pileus width, and time to harvest were analyzed, and then optimized by the simple lattice method. In respect to the time to harvest, it was demonstrated that when the three substrates were used separately, the growth period associated with the soybean straw substrate was the shortest, followed by the corn straw, and the wheat straw. It was concluded that soybean straw may be beneficial in shortening the cultivation cycle of $P$. pulmonarius. Furthermore, the time to harvest was shortest when 100\% soybean straw was used as the primary ingredient. The mycelial growth rate was the greatest on the wheat straw, followed by corn straw and soybean straw. The mushroom yield was the greatest when grown on the soybean straw, followed by corn straw and wheat straw (Additional file 1: Table S8). These results indicated that different substrate components had varying effects on several important agronomic traits. This may be attributed to their different nutritional components and structures, such as the differing contents of cellulose and lignin (Naraian et al. 2009). The carbon to nitrogen ratio $(\mathrm{C} / \mathrm{N})$ of the wheat straw, corn straw, and soybean straw was $70.92,39.30$, and 75.03 , respectively (Miu 2015; Wu et al. 2018). The cellulose content of the wheat straw, corn straw, and soybean straw was $39.26 \%$, $37.15 \%$, and $30.83 \%$, respectively, and the lignin content of the wheat straw, corn straw, and soybean straw was $22.10 \%, 22.14 \%$, and $32.80 \%$, respectively (Miu 2015; Wu et al. 2018). The cellulose content of the soybean straw was the lowest, but its lignin content was the highest. It can be inferred that the substrate with higher lignin content could be more conducive to growth in terms of stipe length, pileus length, pileus width, yield increases, and by decreasing the time to harvest of $P$. pulmonarius. The difference in the $\mathrm{C} / \mathrm{N}$ ratio is also an important factor affecting the evaluation index of edible fungi (Yang et al. 2013). The soybean straw had the greatest influence the time to harvest, stipe length, pileus length, pileus width, and yield, indicating that the soybean straw is a suitable cultivation matrix. However, in addition to the soybean straw, wheat straw and corn straw can also be used together to maximize this impact.

In conclusion, this study demonstrated that the overall yield of $P$. pulmonarius could be improved by optimizing the substrate formula for cultivation; thus, we propose using alternatives to sawdust and cottonseed hulls. The amount of the agro-residue (wheat straw, soybean straw, and corn straw) used had a significant influence on the dependent variables. Wheat straw had the greatest effect on mycelial growth rate, followed by corn straw and soybean straw. Soybean straw had the greatest effect on time to harvest, stipe length, pileus length, pileus width, and yield, followed by corn straw and wheat straw. By verifying the optimized high yield comprehensive substrate formula, it was concluded that these agro-residues (i.e., wheat straw, corn straw, and soybean straw) may be used to replace sawdust and cottonseed hulls as the main cultivation substrates of $P$. pulmonarius. The findings of the present study provide a theoretical basis for the "replacing wood for grass" project on edible mushroom cultivation. Future research should explore the mechanisms by which wood rot fungi decompose grasses, and screen to select candidate wood rot fungi strains that can be cultivated with agricultural residues.

\section{Supplementary information}

Supplementary information accompanies this paper at https://doi. org/10.1186/s13568-019-0907-1.

Additional file 1: Table S1. Variance Analysis of the Quadratic Polynomial Regression Model for Time to Harvest. Table S2. Variance Analysis of the Quadratic Polynomial Regression Model for Stipe Length. Table S3. Variance Analysis of the Quadratic Polynomial Regression Model for Pileus Length. Table S4. Variance Analysis of the Quadratic Polynomial Regression Model for Pileus Width. Table S5. Variance Analysis of the Quadratic Polynomial Regression Model for Mycelial Growth Rate. Table S6. Variance Analysis of the Quadratic Polynomial Regression Model for Yield. Table S7. Comparison of Main Agronomic Traits Between the HC Formula and the CK Substrate Formula. Table S8. The Influence of the Three Agro-residues as $100 \%$ of the Main Ingredient on Each Evaluation Index. 


\section{Abbreviations}

BE: biological efficiency; CK: control; OFAT: one-factor-at-a-time; PDA: potato dextrose agar; SNK: Student-Newman-Keuls.

\section{Acknowledgements}

We thank Huang Jing for her help with the experimental techniques.

\section{Authors' contributions}

NW and FHT conceived and designed the experiments, performed the experiments, analyzed the data, wrote the paper, prepared figures and/or tables, these authors contributed equally to this work; OM, BS and CWJ conceived and designed the experiments; JQY, RNL and ZQ performed the experiments; $C T L$ conceived and designed the experiments, analyzed the data, contributed reagents/materials/analysis tools, wrote the paper, prepared figures and/or tables, reviewed drafts of the paper. All authors read and approved the final manuscript

\section{Funding}

This work was supported National Key Research and Development Program of China (2017YFD0601002), Collaborative Innovation for "Juncao" Ecology Industry, China (K80ND8002-JCZXGGKT05), University S \& T Innovation Platform of Jilin Province for Economic Fungi (\#2014B-1), Special Fund for Agro-scientific Research in the Public Interest (201503137).

\section{Availability of data and materials}

The datasets supporting the conclusions of this article are included within the article.

\section{Ethics approval and consent to participate}

This article does not contain studies with human participants or animals performed by any of the authors.

\section{Competing interests}

The authors declare that they have no competing interests.

\section{Author details}

${ }^{1}$ Engineering Research Center of Edible and Medicinal Fungi, Ministry of Education, Jilin Agricultural University, Changchun 130118, China. ${ }^{2}$ Institute of Microbiology Guangxi Academy of Agricultural Sciences, Nanning 530007, Guangxi, China. ${ }^{3}$ College of Life Sciences, Jilin Agricultural University, Changchun 130118, China.

Received: 9 May 2019 Accepted: 30 October 2019

Published online: 14 November 2019

\section{References}

Bhattacharjya DK, Paul RK, Miah MN, Ahmed KU (2015) Comparative study on nutritional composition of oyster mushroom (Pleurotus ostreatus Fr.) cultivated on different sawdust substrates. Bioresour Commun 1(2):93-98

Fan LJ, Pan ZH, Gao WX, Jin QL, Feng WL, Song TT, Shen YY, Cai WM (2016) The comparison tests of three strains of Pleurotus geesteranus production. Edible Med Mushrooms 4:258-259

Ge L (2015) Study on varieties optimizing and high efficient key cultivation techniques of Pleurotus geesteranus. Agricultural University of Hebei, Baoding

Hoa HT, Wang CL, Wang CH (2015) The effects of different substrates on the growth, yield, and nutritional composition of two oyster mushrooms (Pleurotus ostreatus and Pleurotus cystidiosus). Mycobiology 43(4):423-434

Lechner BE, Wright JE, Albertoì E (2004) The genus Pleurotus in Argentina. Mycologia 96(4):845-858

Li Y, Li TH, Yang ZL, Tolgor Bau, Dai YC (2015) Atlas of Chinese macrofungal resources. Central Plains farmers Press, Henan

Lin ZX (2009) Juncao technology. China Agricultural Science and Technology Press, Beijing

Liu LQ, Zhang ZJ, Zi HJ, Zhou YB, Wang WZ, Wei XS, Wang M, Li FM (2011) Preliminary study on the cultivation of Pleurotus eryngii with soybean straw. Edible Fungi China 30(2):33
Lundstedt T, Seifert E, Abramo L, Thelin B, Nyströma Å, Pettersen J, Bergman $R$ (1998) Experimental design and optimization. Chemometr Intell Lab 42(1-2):3-40

Miu WJ (2015) Physicochemical composition and energy potential of main crop straw and stalk. Doctoral Dissertation of China Agricultural University, Beijing

Moonmoon M, Uddin MN, Ahmed S, Shelly NJ, Khan MA (2010) Cultivation of different strains of king oyster mushroom (Pleurotus eryngii) on saw dust and rice straw in Bangladesh. Saudi J Biol Sci 17(4):341-345

Naraian R, Sahu R, Kumar S, Garg S, Singh C, Kanaujia R (2009) Influence of different nitrogen rich supplements during cultivation of Pleurotus forida on corn cob substrate. Environmentalist 29:1-7

Nguyen TK, Im KH, Choi J, Shin PG, Lee TS (2016) Evaluation of antioxidant, anti-cholinesterase, and anti-inflammatory effects of culinary mushroom Pleurotus pulmonarius. Mycobiology 44(4):291-301

Ni D (2016) The biological characteristics and cultivation techniques of Pleurotus pulmonarius. J Changjiang Vegetables 22:70-72

Oliveira SS, Da CSMG, Edmar C (2002) Chemical composition of Pleurotus pulmonarius (Fr.) Quél. substrates and residue after cultivation. Braz Arch Biol Techn 45(4):531-535

Olufemi AE, Terry AOA, Kola OJ (2012) Anti-leuCultivation of different strains of king oyster mushroom (Pleurotus eryngii) on saw dust and rice straw in Bangladeshkemic and immunomodulatory effects of fungal metabolites of Pleurotus pulmonarius and Pleurotus ostreatus on benzene-induced leukemia in Wister rats. Korean J Hematol 47(1):67-73

Papadaki A, Kachrimanidou V, Papanikolaou S, Philippoussis A, Diamantopoulou P (2019) Upgrading grape pomace through Pleurotus spp. cultivation for the production of enzymes and fruiting bodies. Microorganisms 7(7):207

Pedri ZC, Lozano LM, Hermann KL, Helm CV, Peralta RM, Tavares LB (2015) Influence of nitrogen sources on the enzymatic activity and grown by Lentinula edodes in biomass Eucalyptus benthamii. Braz J Biol Revista brasleira de biologia 75(4):940-947

Rezaeian S, Pourianfar HR (2016) A comparative study on bioconversion of different agro wastes by wild and cultivated strains of flammulina velutipes. Waste Biomass Valoriz 8(8):2631-2642

Sanderson MA, Reed RL (2000) Switchgrass growth and development: water, nitrogen, and plant density effects. J Range Manage 53(2):221-227

Sarker NC, Hossain MM, Sultana N, Mian IH, Karim AJMS, Amin SMR (2007) Impact of different substrates on nutrient content of Pleurotus ostreatus (Jacquin ex Fr.) kummer. Bangladesh J Mushroom 1(2):35-38

Scheffe H (1963) The simplex-centroid design for experiments with mixtures. J Roy Stat Soc D-sta 25(2):235-263

Singh SK, Singh SK, Tripathi VR, Khare SK, Garg SK (2011) Comparative onefactor-at-a-time, response surface (statistical) and bench-scale bioreactor level optimization of thermoalkaline protease production from a psychrotrophic Pseudomonas putida skg-1 isolate. Microb Cell Fact 10(1):114

Smiderle FR, Olsen LM, Ruthes AC, Czelusniak PA, Santana-Filho AP, Sassaki GL, Gorin PAJ, lacomini M (2012) Exopolysaccharides, proteins and lipids in Pleurotus pulmonarius submerged culture using different carbon sources. Carbohyd Polym 87(1):368-376

Song B, Ye JQ, Sossah FL, Li CT, Li D, Meng LS, Xu S, Fu YP, Li Y (2018) Assessing the effects of different agro-residue as substrates on growth cycle and yield of Grifola frondosa and statistical optimization of substrate components using simplex-lattice design. AMB Express 8:46

Souza CGMD, Zilly A, Peralta RM (2002) Production of laccase as the sole phenoloxidase by a Brazilian strain of Pleurotus pulmonarius in solid state fermentation. J Basic Microbiol 42(2):83-90

Springer TL, Dewald CL, Simsand PL, Gillen RL (2003) Does plant population density affect the forage yield of eastern gamagrass? Crop Sci 43:2206-2211

Stanley HO, Umolo EA, Stanley CN (2011) Cultivation of oyster mushroom (Pleurotus pulmonarius) on amended corncob substrate. Agric Biol JN Am 2(10):1336-1339

Velázquez-Cedeño MA, Mata G, Savoie J-M (2002) Waste-reducing cultivation of pleurotus ostreatus, and pleurotus pulmonarius, on coffee pulp: changes in the production of some lignocellulolytic enzymes. World J Microb Biot 18(3):201-207

Wahab NAA, Abdullah N, Aminudin N (2014) Characterisation of potential antidiabetic-related proteins from Pleurotus pulmonarius (Fr.) Quél. (grey 
oyster mushroom) by MALDI-TOF/TOF mass spectrometry. Biomed Res Int 2014:131607

Wu SJ (2011) Screening of the Pleurotus cornucopiae liquid medium. North Hortic 15:215-216

Wu N, Tian FH, Jia CW, Wang Y, Li CT (2018) Mixture design optimization of "replacing wood by grass" formula for mycelium growth of Pleurotus djamor. Microbiol China. https://doi.org/10.13344/j.microbiol.china.18050 9

Xu W, Huang JJ, Cheung PC (2012) Extract of Pleurotus pulmonarius suppresses liver cancer development and progression through inhibition of VEGFInduced PI3 K/AKT signaling pathway. PLoS ONE 7(3):34406

Yang W, Guo F, Wan Z (2013) Yield and size of oyster mushroom grown on rice/ wheat straw basal substrate supplemented with cotton seed hull. Saudi J Biol Sci 20(4):333-338

Yang JJ, Zhang GX, Yang Q, Hu J (2016) Biology research of Pleurotus ostreatus cultivated in different raw materials. J North For Univ 31 (3):170-174
Zhang M, Zhu L, Cui SW, Wang Q, Zhou T, Shen H (2011) Fractionation, partial characterization and bioactivity of water-soluble polysaccharides and polysaccharide-protein complexes from Pleurotus geesteranus. Int J Biol Macromol 48(1):12

Zhang AQ, Xu M, Fu L, Sun PL (2013) Structural elucidation of a novel mannogalactan isolated from the fruiting bodies of Pleurotus geesteranus. Carbohyd Polym 92(1):236-240

Zhang S, Liu B, Liu JH, Wu YH (2016) Cultivation technology improvement of Pleurotus geesteranus. J Anhui Agric 44(36):63-64

\section{Publisher's Note}

Springer Nature remains neutral with regard to jurisdictional claims in published maps and institutional affiliations.

\section{Submit your manuscript to a SpringerOpen ${ }^{\circ}$ journal and benefit from:}

- Convenient online submission

- Rigorous peer review

- Open access: articles freely available online

- High visibility within the field

- Retaining the copyright to your article

Submit your next manuscript at $\boldsymbol{\nabla}$ springeropen.com 